
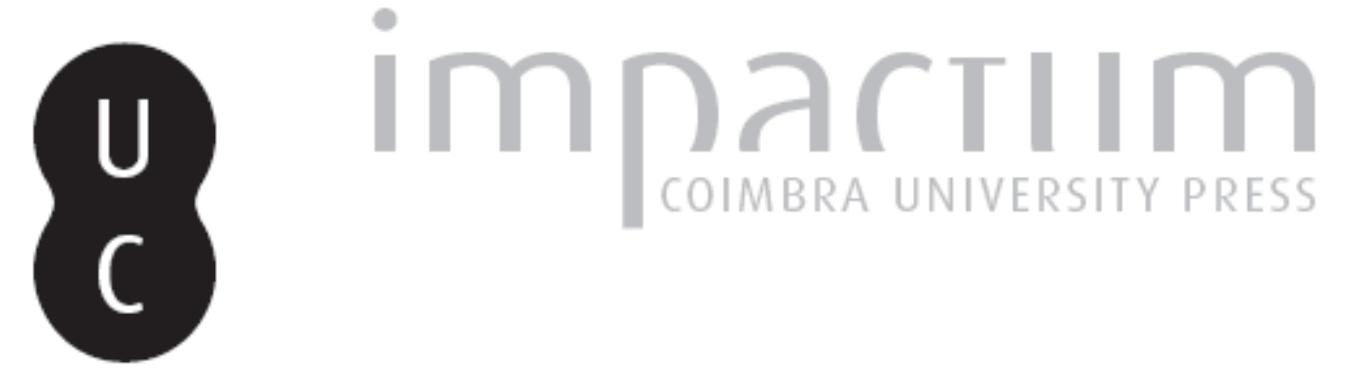

\title{
Fragmentación y edición en el Libro del Desasosiego
}

\author{
Autor(es): $\quad$ Giménez, Diego
}

Publicado por: Centro de Literatura Portuguesa

URL persistente:

URI:http://hdl.handle.net/10316.2/29983

DOI:

DOI:http://dx.doi.org/10.14195/2182-8830_1-1_3

Accessed : $\quad$ 26-Apr-2023 04:30:38

A navegação consulta e descarregamento dos títulos inseridos nas Bibliotecas Digitais UC Digitalis, UC Pombalina e UC Impactum, pressupõem a aceitação plena e sem reservas dos Termos e Condições de Uso destas Bibliotecas Digitais, disponíveis em https://digitalis.uc.pt/pt-pt/termos.

Conforme exposto nos referidos Termos e Condições de Uso, o descarregamento de títulos de acesso restrito requer uma licença válida de autorização devendo o utilizador aceder ao(s) documento(s) a partir de um endereço de IP da instituição detentora da supramencionada licença.

Ao utilizador é apenas permitido o descarregamento para uso pessoal, pelo que o emprego do(s) título(s) descarregado(s) para outro fim, designadamente comercial, carece de autorização do respetivo autor ou editor da obra.

Na medida em que todas as obras da UC Digitalis se encontram protegidas pelo Código do Direito de Autor e Direitos Conexos e demais legislação aplicável, toda a cópia, parcial ou total, deste documento, nos casos em que é legalmente admitida, deverá conter ou fazer-se acompanhar por este aviso.

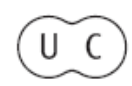




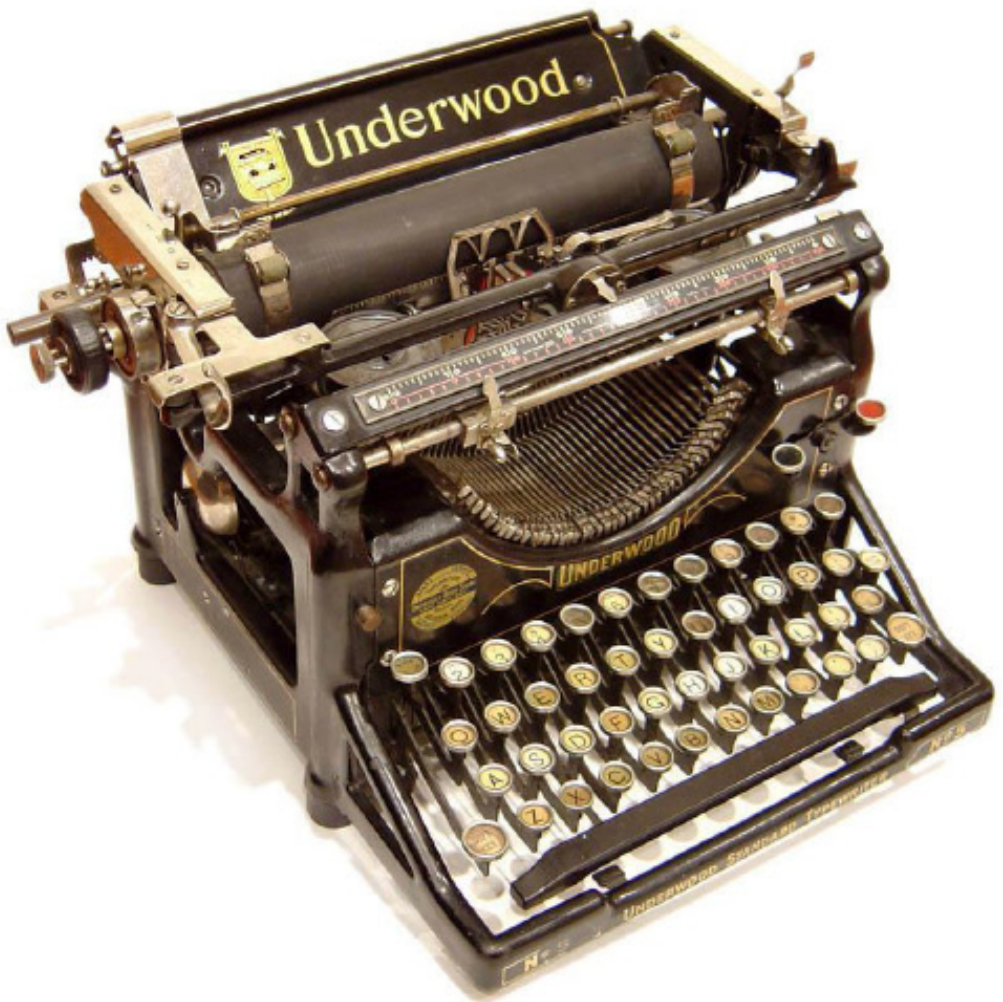

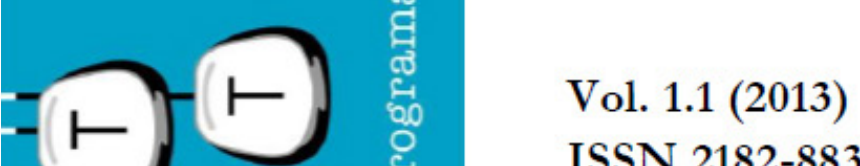

ISSN 2182-8830

'Estranhar Pessoa com

as Materialidades da Literatura'

Orgs. Manuel Portela \&

Osvaldo Manuel Silvestre 


\title{
Fragmentación y Edición en el Libro del Desasosiego DIEGO GIMÉNEZ
}

\author{
CLP | Universidad de Barcelona
}

\begin{abstract}
Resumen
El presente artículo sostiene que las diferentes ediciones del Livro do Desassossego son en cierta manera una desfiguración en la medida que el editor toma decisiones que el escritor no tomó sobre variables textuales y selección de fragmentos. ${ }^{1}$ Dentro de la modernidad, donde el «Livro» acontece como horizonte utópico, Pessoa presenta una escritura que no cierra y que, por tanto, deja abierta a la interpretación. Asimismo, intentaré desarrollar cómo la mediación (interpretación) sobre un texto queda reflejada en elementos gráficos que crean significado. El proceso de escritura pasa por diferentes etapas desde el momento inicial en que el escritor plasma sobre el papel la primera letra hasta la publicación de lo escrito en el formato que sea. La edición digital puede ser concebida como una forma de poner de manifiesto que la escritura se basa en un proceso de selección. Palavras-chave: Fernando Pessoa; Livro do Desassossego; Interpretação; Fragmento; Edição Electrónica.
\end{abstract}

\section{Abstract}

This article argues that the various editions of the Book of Disquiet represent some defacement. The editor makes decisions that the writer did not take on textual variables and selection of fragments. In modernity the "book" emerges as a utopian horizon. Pessoa's writing is not finished and, therefore, remains open to interpretation. Also, I'll try to show how mediation (interpretation) upon a text is reflected in graphic elements that create meaning. The writing process goes through various stages from the initial inscription of letters on paper to the moment of publication in whatever format. A digital edition can be conceived as a way to show that writing is based on a selection process. Keywords: Fernando Pessoa; Livro do Desassossego; Interpretation; Fragment; Electronic Editing.

“Plain text is never plain”. - Sandy Baldwin (2013)

\section{Mediación y significado}

\section{${ }^{6} \mathrm{M}$ \\ eaning is produced, after all, not exhumed", afirma Johanna Drucker en «Graphical Readings and the Visual Aesthetics of Textuality» (2006), un artículo en que la ensayista americana afirma que los elementos gráficos son una parte importante de la producción semántica, por lo que deberían ser entendidos}

${ }^{1}$ Artigo produzido no âmbito do projeto de investigação 'Nenhum Problema Tem Solução: Um Arquivo Digital do Livro do Desassossego' (referência PTDC/CLELLI/118713/2010). Projeto financiado pela FCT e cofinanciado pelo FEDER, através do Eixo I do Programa Operacional Fatores de Competitividade (POFC) do QREN, COMPETE: FCOMP-01-0124-FEDER-019715. 
como parte integrante de la textualidad. De manera similar, Paul De Man (2007) sostiene que la escritura autobiográfica sigue estructuras tropológicas de significación de tal manera que la identidad es una máscara moldeada narrativamente mediante un proceso especular en que el escritor se desdobla y se convierte en el tema de su propia indagación y construcción. La identidad es retóricamente producida, no exhumada. Siguiendo el juego de paralelismos, en 1967 Italo Calvino pronunció, en diferentes partes de Italia, una conferencia bajo el título "Cibernética y fantasmas» en la que entre otras cosas afirmó que el yo del escritor al escribir se disolvía y que la personalidad del mismo era inherente al acto mismo de escribir, un producto y un modo del proceso de escritura (1967: 215).

En el presente artículo sostengo por un lado que el Livro do Desassossego de Fernando Pessoa, es producido, no exhumado, dado el carácter inacabado del mismo. La mediación sobre el texto pessoano no está exenta de interpretación. La mediación representa estados: una primera mediación sobre el texto que es la corrección que el propio autor ejerce sobre lo escrito. Un proceso de emergencia de la subjetividad como resultado de la toma de consciencia sobre lo escrito en que el escritor deviene en lector de su escritura y donde cada subrayado representa una marca sobre el texto; una segunda etapa que es la mediación editorial que presenta una interpretación sobre las variables textuales (donde, más allá de criterios estéticos, se atienden también a criterios económicos y sociales) y, por fin, una última etapa en que la digitalización se presenta como una forma de crear una metarepresentación de los procesos de edición, representando el texto a través de la codificación electrónica.

Por otro lado, intentaré explicar cómo la mediación sobre un texto queda reflejada en elementos gráficos que crean significado. El proceso de escritura pasa por diferentes etapas desde el momento inicial en que el escritor plasma sobre el papel la primera letra hasta la publicación de lo escrito en el formato que sea. La edición digital puede ser concebida como una forma de poner de manifiesto que la escritura se basa en un proceso de selección. Para ello me valdré de la tesis desarrollada por Calvino, aplicada a Fernando Pessoa.

¿En qué medida se puede sostener que la escritura en Pessoa no se cierra y en qué medida se puede afirmar que de haber tenido más tiempo hubiese terminado el Livro? Pessoa concibe el Livro sólo como horizonte utópico, por tanto, inalcanzable. Como demuestra Pedro Sepúlveda en su tesis (Sepúlveda, 2012), Pessoa trabaja con un determinado concepto de libro que asocia a cada uno de los heterónimos, una escritura diferenciada estilísticamente y asociada al espacio material del libro. La noción de libro es una de las guías de su escritura. Pero en todo caso, se tiene que entender como un proyecto en construcción que no llega a concretarse nunca. Lo que es característico en la escritura de Pessoa es que no cesa de escribirse. Para demostrar esta serie de hipótesis abordaré la relación entre escritura, edición y digitalización de 
una obra, entendida esta última como el resultado de un proceso de selección y mediación, esto es, también, de interpretación.

\section{Los libros del desasosiego}

Una gráfica comparativa de la selección de fragmentos entre las principales ediciones (Coelho, 1982; Sobral Cunha, 1998; Zentih, 2009 y Jerónimo Pizarro, 2010) puede ayudar a ilustrar la divergencia de criterios sustentada en la base textual (Gráfica 1):

\begin{tabular}{|c|c|c|c|c|c|}
\hline LdoD & Año & Editora & $\begin{array}{c}\text { Número de } \\
\text { fragmentos }\end{array}$ & $\begin{array}{c}\text { Criterio de } \\
\text { ordenación }\end{array}$ & Ortografía \\
\hline Coelho & 1982 & Ática & 520 & $\begin{array}{c}\text { "Manchas } \\
\text { temáticas" }\end{array}$ & Antigua \\
\hline Cunha & $\begin{array}{r}1997 \\
-2008\end{array}$ & Relógio d'Água & 723 & Cronológico & Moderna \\
\hline Zenith & $\begin{array}{r}1998 \\
-2009\end{array}$ & Assírio \& Alvim & $\begin{array}{c}(481+33) \\
514\end{array}$ & Subjetivo & Moderna \\
\hline Pizarro & 2010 & $\begin{array}{c}\text { Imprensa Nacional } \\
\text { Casa da Moeda }\end{array}$ & 586 & Cronológico & Antigua \\
\hline
\end{tabular}

Gráfica 1. Cuadro comparativo del número de fragmentos seleccionados por cada editor, de los criterios de ordenación y de la ortografía respetada.

Por otro lado, la ordenación y secuenciación de los fragmentos también es dispar. Dos gráficas ilustran también las diferencias en la ordenación de cinco fragmentos que Pessoa publicó en vida (Gráficas 2 y 3):

\begin{tabular}{|l|c|c|c|c|c|}
\hline $\begin{array}{c}\text { Fragmentos publicados por Pessoa } \\
\text { en la revista Descobrimento }\end{array}$ & $\begin{array}{c}\text { Pessoa } \\
\mathbf{( 1 9 3 1 )}\end{array}$ & $\begin{array}{c}\text { Coelho } \\
\mathbf{( 1 9 8 2 )}\end{array}$ & $\begin{array}{c}\text { Cunha } \\
\mathbf{( 2 0 0 8 )}\end{array}$ & $\begin{array}{c}\text { Zenith } \\
\mathbf{( 2 0 0 9 )}\end{array}$ & $\begin{array}{c}\text { Pizarro } \\
\mathbf{( 2 0 1 0 )}\end{array}$ \\
\hline Prefiro a prosa ao verso & frg. 1 & frg. 13 & pg. 493 & frg. 234 & frg. 331 \\
\hline Nuvens... Hoje tenho consciência & frg. 2 & frg. 154 & pg. 478 & frg. 216 & frg. 332 \\
\hline Gosto de dizer & frg. 3 & frg. 15 & pg. 495 & frg. 261 & frg. 333 \\
\hline Sim, é o poente. Chego à foz & frg. 4 & frg. 181 & pg. 492 & frg. 232 & frg. 334 \\
\hline Assim como, quer o saibamos & frg. 5 & frg. 239 & pg. 481 & frg. 219 & frg. 335 \\
\hline
\end{tabular}

Gráfica 2. Cuadro comparativo de la secuencia de fragmentos por Pessoa y las diferentes ediciones. 


\begin{tabular}{|l|c|c|c|c|c|}
\hline \multicolumn{1}{|c|}{ Fragmentos Descobrimento } & $\begin{array}{c}\text { Pessoa } \\
(1931)\end{array}$ & $\begin{array}{c}\text { Coelho } \\
(1982)\end{array}$ & $\begin{array}{c}\text { Cunha } \\
(2008)\end{array}$ & $\begin{array}{c}\text { Zenith } \\
(2009)\end{array}$ & $\begin{array}{c}\text { Pizarro } \\
\text { (2010) }\end{array}$ \\
\hline Prefiro a prosa ao verso & frg. 1 & frg. 13 & pg. 493 & frg. 234 & frg. 331 \\
\hline Nuvens... Hoje tenho consciência & frg. 2 & frg. 154 & pg. 478 & frg. 216 & frg. 332 \\
\hline Gosto de dizer & frg. 3 & frg. 15 & pg. 495 & frg. 261 & frg. 333 \\
\hline Sim, é o poente. Chego à foz & frg. 4 & frg. 181 & pg. 492 & frg. 232 & frg. 334 \\
\hline Assim como, quer o saibamos & frg. 5 & frg. 239 & pg. 481 & frg. 219 & frg. 335 \\
\hline
\end{tabular}

Gráfica 3: Cuadro comparativo cromático de la secuencia de fragmentos por Pessoa y las diferentes ediciones.

Considero que todos los fragmentos que Pessoa publicó en vida (12) son especialmente relevantes porque pueden alumbrar muchos aspectos de la intención del escritor. Por ejemplo se percibe en los fragmentos cómo la atribución autoral se decanta, en la prosa tardía, por Bernardo Soares, que es resultado del proceso de escritura (Giménez, 2012). Por lo que se refiere a la ordenación, las gráficas 2 y 3 muestran con claridad la divergencia de criterios. Sólo la publicación de Pessoa y la edición de Pizarro presentan los fragmentos secuenciados en el mismo orden. Las otras ediciones alternan la secuencia y la ordenación entre el resto de fragmentos de las respectivas compilaciones.

Coelho justifica su ordenación apelando a "manchas temáticas", una fórmula que intenta complacer a investigadores y lectores:

Evitando um didactismo abusivo, ordenei o Livro do Desassossego por manchas temáticas, sem vedações a separá-las, sugerindo nexos e contrastes pela simples justaposição, colocando todavia no começo do itinerário textos e fragmentos a que atribuí uma função periférica, introdutória, e levando o leitor a concentrar a atenção em zonas de relativa homogeneidade, com textos, por exemplo, de carácter autobiográfico e confessional, textos sobre a diversidade do eu e a sua descoberta através do disfarce, textos sobre o eu e a circunstância na roda dos dias, etc. Trata-se, claro, duma proposta de leitura apresentada a título pessoal, que de nenhum modo ambiciona ser exclusiva os se pretende «a melhor». (1982: XXXII). 
Sobral Cunha divide el Livro en dos grandes bloques cuya autoría se atribuye a Vicente Guedes y Bernardo Soares respectivamente. La base de la ordenación de Cunha es cronológica:

Os dois ciclos do grande corpo textual - definidos pela sucessão dos documentos numa ordem cronológica, a partir da datação original dos trechos, ou conjecturada pela responsável da edição a partir de realidades e conexões comuns - são balizados pelos anos correspondentes aos períodos 1912-1921 (com apenas quatro documentos datados) e 19281934, cuja datação se tornou frequente a partir de Março de 1929, intensificando-se nos anos posteriores. (2008: 33).

Zenith por su parte apela a los trechos datados de la última fase para armar un esqueleto soaresiano:

Entre estes trechos, mantidos em ordem cronológica, intercalam-se os outros, quer contemporâneos quer muito anteriores (e inclusive pouquíssimos trechos datados dos anos 10). Deste modo os mais antigos talvez possam, por uma especie de osmose, adquirir algo da «vera piscologia» de Bernardo Soares que Pessoa quis introduzir na revisão de texto que não chegou a fazer. (2009: 37).

El editor reconoce que sería posible establecer una cronología aproximada de los fragmentos a partir de un análisis minucioso de los papeles, de las tintas y de la caligrafía de los originales, pero duda que sea la mejor manera de organizar los trechos.

La edición crítica genética de Jerónimo Pizarro (2010) presenta una ordenación cronológica y la justifica apelando al respeto a la base fragmentaria de la obra para poder ofrecer al lector todos los elementos posibles para que éste adopte su propia lectura:

A organização do presente volume [...] procura ser cronológica e o mais objectiva possível. [...] Esta edição também procura «um grande compromisso entre materialidade e sentido»; e a sua organização também não responde a uma leitura subjectiva dos conteúdos das peças individuais, senão a um estudo cuidadoso de cada um dos suportes. (2010: 9).

Los fragmentos publicados en Descobrimento (Gráfica 2 y 3) podrían señalar la intención de publicar los fragmentos del Livro de forma numerada, aún así, las indicaciones de Pessoa sobre cómo organizar el Livro son ambiguas. Todas las ediciones presentan elementos valiosos para la investigación de la obra de Pessoa, cuyo análisis no se puede desprender de la 
historia de su edición. La pregunta es si hay alguna manera de respetar la base fragmentaria y organizativamente ambigua del Livro.

\section{De la ordenación al fragmento}

Hemos analizado los criterios de ordenación y selección de los fragmentos, pero las diferencias se hallan no sólo en lo macro sino también en lo micro. La estructura de los fragmentos hace necesaria la interpretación dentro del mismo texto. Los editores tienen que escoger sobre diferentes variables textuales y hacer de puente entre aquello que Pessoa no cerró.

Si analizamos uno de los fragmentos publicados en vida, por ejemplo el publicado en $A$ Revista, sabemos que se guardan tres testimonios materiales: un manuscrito, un datiloscrito y la publicación en la revista (Figura 1). En base a estos tres testimonios se constituyen las variables textuales generadas por cada edición. Cuatro textos diferentes sobre una misma base material.

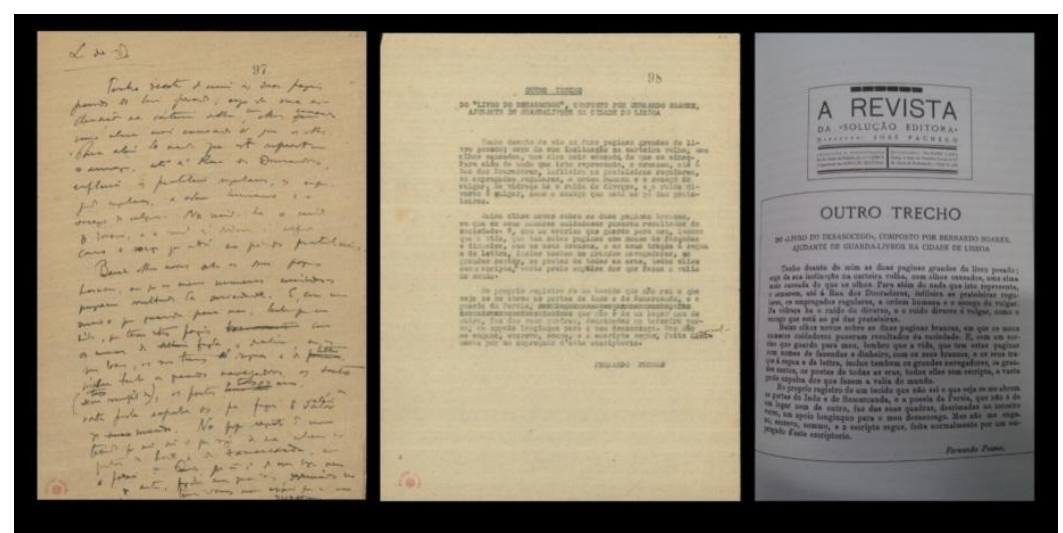

Figura 1.

El primer testimonio ${ }^{2}$ pertenece a la prosa tardía del Livro. Está escrito en tinta negra en el verso de un manifiesto de estudiantes. Lleva indicado que el fragmento pertenece al LdoD. El texto, en ortografía antigua ${ }^{3}$, se precipita agónico hacia el final de la hoja para entrar dentro de los límites de la misma. Presenta siete correcciones entre las que encontramos substituciones, tachaduras y dudas. Pessoa primero tacha la palabra 'brancamente' y 'dinheiro'. Después substituye el artículo 'de' por el artículo 'á' y cambia 'penna' por 'letra'. A continuación pone entre paréntesis la frase 'sem scripta'

${ }^{2}$ Referencia de la Biblioteca Nacional de Portugal: bn-acpc-e-e3-2-1-91_0011_6_t24C-R0150

${ }^{3}$ Pessoa nunca acató la reforma ortográfica de 1911, habiendo publicado Mensagem, a finales de 1934, aún con la antigua ortografía. 
sobre la que escribe 'todos'. Después substituye 'sem let' por 'todas las eras'. Luego suma 'valía' al 'valor' y tacha un 'mun' antes de escribir 'mundo'.

Estas correcciones, en forma de marca sobre lo escrito, representan ese primer momento de mediación sobre el texto al que hacíamos referencia al principio del artículo. Un primer proceso en que la subjetividad del escritor queda fijada en forma de cicatriz que señala cómo el proceso de escritura es un proceso de selección. Casi podemos imaginar a Pessoa releyendo el texto, aprobando, rechazando y substituyendo palabras en una toma de consciencia sobre lo escrito. Si recordamos, uno de los postulados de Pessoa, que menciona Lind, la construcción estética pasa por la consciencia de la consciencia que permite dar forma a la sensación en forma de escritura (Lind, 1970: 171).

El segundo testimonio ${ }^{4}$ es un datiloscrito en tinta negra. También inscrito en el verso de un manifiesto de estudiantes. Sigue la ortografía antigua y afirma en el título que se trata de otro trecho del Livro del Desasocego compuesto por Bernardo Soares. El texto presenta como diferencia con el testimonio anterior la tachadura de la frase 'seu logar nem era o meu sonho, faz de minhas quadras intimas' y la suma de una frase que el otro texto no contiene: 'Mas não me engano, escrevo, sommo, e a escripta segue, feita normalmente por um empregado d'este escriptorio'. El fragmento está finalmente firmado por Fernando Pessoa.

El último testimonio que se guarda sobre el fragmento es el publicado en A Revista, propiedad de «Solução Editora», nº. 4. Lisboa: 1929, p. 42., y que representa una nueva fase de mediación en la que el texto es preparado para una publicación. La hoja consta de las mismas referencias que el datiloscrito: el título con referencias al Livro do Desasocego, a la composición de Bernardo Soares, a la profesión y procedencia del heterónimo y finalmente la firma de Fernando Pessoa.

Se podría pensar que sobre estos tres testimonios hay elementos suficientes para presentar cierta unidad sobre la edición del texto. Pero, cómo veremos, no es así. Las diferencias entre las ediciones van más allá de una diferente ordenación del fragmento sino que también presentan diferencias significativas en la composición.

\footnotetext{
${ }^{4}$ Referencia de la Biblioteca Nacional de Portugal: bn-acpc-e-e3-2-1-91_0013_7_t24C-R0150
} 


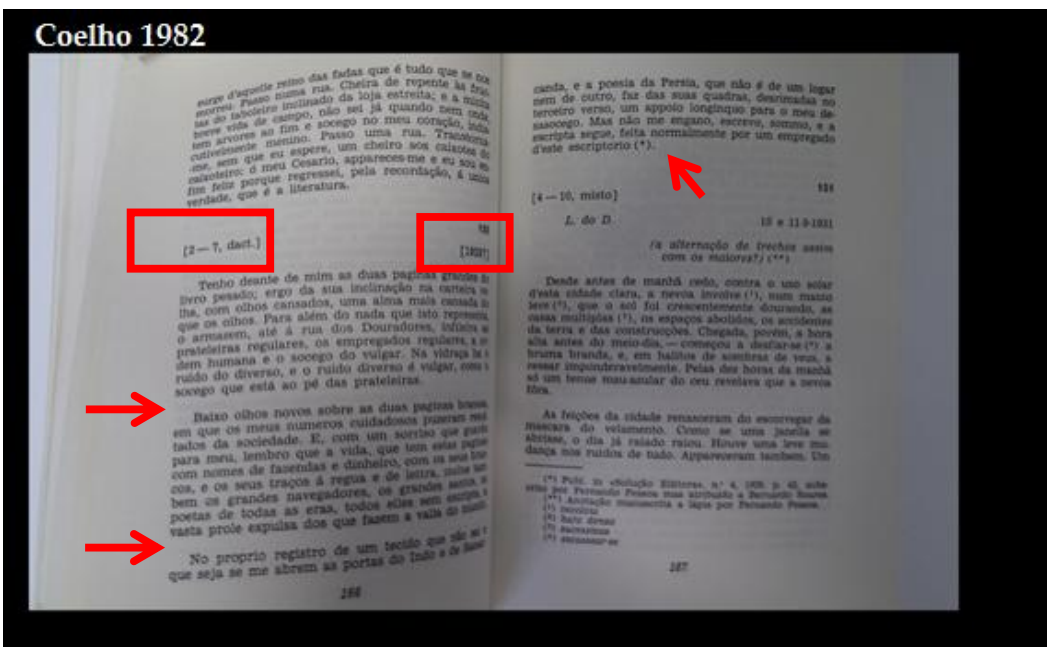

Figura 2.

La edición de Coelho (Figura 2) hace referencia al testimonio material sobre el que basa su transcripción [2-7. Dact.], numera el fragmento (150, publicado en la página 166), conjetura la fecha del mismo [1929?] y hace referencia (*) a la publicación del fragmento en A Revista. Otra de las características en la edición de 1982 es que separa los párrafos del trecho con un espacio. Esta es una interpretación también de los espacios que Pessoa deja entre párrafos. La edición de Coelho respeta la misma distribución de espacios que sigue el testimonio datiloscrito. La interpretación de los espacios como elementos semánticos se hace evidente al comparar como los editores entienden y transcriben dichos espacios. La transcripción respeta la ortografía que Pessoa utilizó y, en este caso, no hace referencia a las correcciones que el mismo Pessoa efectuó.

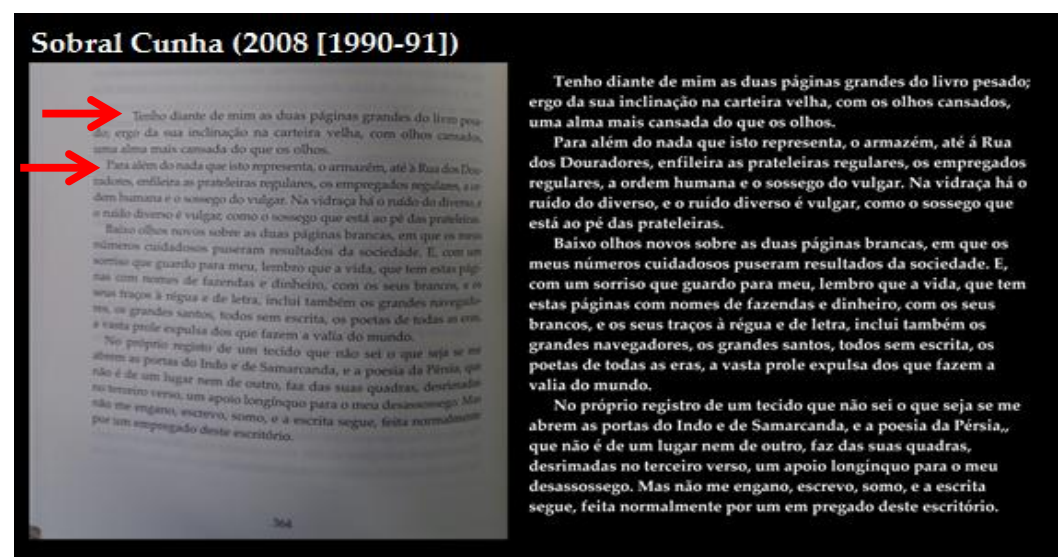

Figura 3. 
La edición de Sobral Cunha no numera los fragmentos, los separa con un doble espacio entre ellos (Figura 3). No hace referencia al testimonio material sobre el que basa su transcripción; no hace referencia explícita a la fecha del fragmento pero, si recordamos que esta edición basa su orden en un orden cronológico, se puede conjeturar en función de la página en la que está publicado el fragmento (364) y actualiza la ortografía a las normas vigentes. En este caso Sobral Cunha no separa los parágrafos, pero marca un punto y aparte que el testimonio original no contiene.

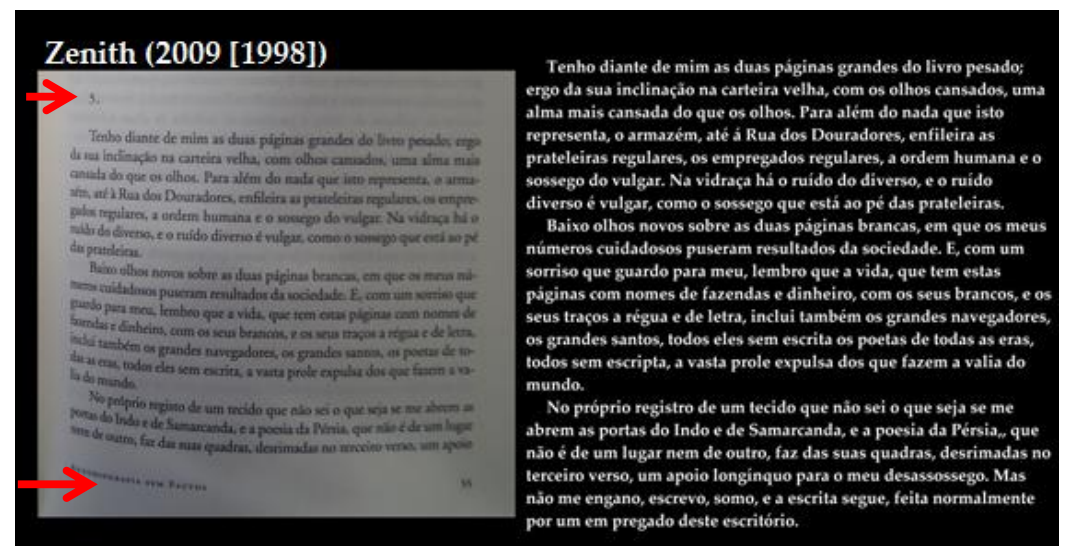

Figura 4.

La edición de Zenith numera los fragmentos (en este caso el número 5) y no hace referencia al testimonio sobre el que basa su transcripción (Figura 4). Se constata también el criterio de ordenación del editor (subjetivo) por el que coloca el fragmento perteneciente a la prosa tardía del Livro al principio de la obra en la página 55. Otra característica de la edición es que el editor separa los fragmentos en dos bloques, uno en que sitúa la mayoría de fragmentos, al que llama 'Autobiografia sem Factos” y en una sección aparte "os «Grandes Trechos», como Pessoa denominou os textos «grandiosos» - não todos os trechos intitulados mas aqueles que, mesmo não sendo tão extensos assim, se integram difícilmente no fio narrativo, por ténue e volúvel que seja." (2009:33). 


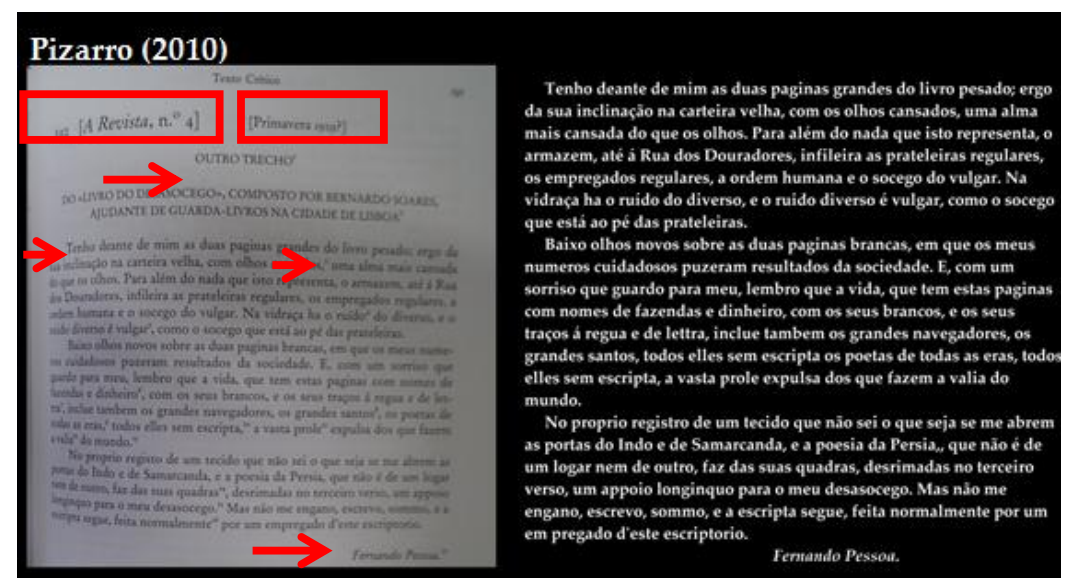

Figura 5.

La edición de Pizarro, cronológica, numera los fragmentos $\left(N^{0} 192\right.$ en la página 191); hace referencia al testimonio material sobre el que basa su transcripción [A Revista, n. ${ }^{\circ} 4$ ], hace referencia a la fecha [Primavera 1929?] y hace referencia en el título al Livro do Desasocego, a Bernardo Soares (procedencia y profesión) (Figura 5). Esta edición se trata de la primera edición crítica genética de la obra y como se aprecia en el texto, las notas señalan las diferencias textuales entre los testimonios originales y las diferentes ediciones. Finalmente el texto también da cuenta de la firma del fragmento.

Siguiendo la argumentación de Drucker, los elementos gráficos constituyen una parte importante en la significación del texto. La numeración, la referencia al testimonio original, la referencia a la fecha o las notas críticas son parte de la semántica del texto de tal manera que no se lee ni se entiende de la misma manera según la edición que se esté usando. En las ediciones de Coelho y de Pizarro se pone de manifiesto de manera directa que se está leyendo una transcripción basada en un original y que, en muchos casos, la lectura que se ofrece es una interpretación. Las ediciones de Sobral Cunha y de Zenith al no hacer referencia a los mismos recursos pueden dar la sensación de cierto consenso sobre el texto y no ponen de manifiesto el grado de interpretación de los mismos. La experiencia de lectura en la edición de Sobral Cunha también es diferente por lo que se refiere a la no numeración de los fragmentos por lo que el texto es leído de forma continua. Así, vemos como los elementos gráficos juegan un papel significativo también en la formación de significado del texto más allá de las decisiones sobre las variables textuales que el contenido textual presenta.

Sobre la base fragmentaria se generan obras que varían unas de otras. No sólo sobre la obra sino también sobre el autor. El ideal positivista de una edición objetiva no existe, siempre está vinculada a la interpretación. Como 
dice Foucault, el objeto no existe como unidad, todo son interpretaciones. Foucault sostiene sobre la obra que:

De hecho, si se habla tan fácilmente y sin preguntarse más de la "obra" de un autor es porque se la supone definida por cierta función de expresión. Se admite que debe haber en ello un nivel (...) en el cual la obra se revela, en todos sus fragmentos, (...) como la expresión del pensamiento, o de la experiencia, o de la imaginación, o del inconsciente del autor (...). Pero también se observa que semejante unidad, lejos de darse inmediatamente, está constituida por una operación interpretativa (...) La obra no puede considerarse ni como unidad inmediata, no como unidad cierta, ni como unidad homogénea. (Foucault, 2005: 39).

Las ediciones del Livro funcionan como la prosopopeya $a^{5}$, dan habla a una entidad muerta y le confieren rostro. Por eso Pizarro habla de construcción póstuma de la figura y de la obra de Pessoa. Los editores intentan organizar y cerrar aquello que Pessoa no cerró. Con cada organización se presenta un rostro diferente. No exhuman una obra sino que, en la medida que median y seleccionan, producen.

\section{Virtualización de un texto que no cesa de escribirse}

Ahora bien, ¿hay alguna otra forma de representar esta variabilidad textual y bibliográfica? La base fragmentaria que el escritor no pudo cerrar ha sido editada y codificada bibliográficamente de manera diferente en cada edición del Livro. A partir de este momento llegamos a la parte final del artículo en la que expondré cómo la base fragmentaria de esta escritura encuentra en la edición digital una nueva forma de representación. Para hablar de este punto primero trataré demostrar qué es una escritura que no cesa de escribirse para después relacionarlo con la virtualización como espacio de esta escritura sin cierre.

En la medida que el editor, y en menor medida también el lector, tienen que imponer cierto sentido a la base fragmentaria del legado, bien sea interpretando, bien sea ordenando, para encausarla dentro de los límites de un libro, estos toman una parte activa en el sentido último de la obra. Es por eso que Pizarro afirmó, en el coloquio sobre el Livro do Desasocego, realizado en la Universidade de Lisboa en diciembre de 2012, que Pessoa nos hacía

\footnotetext{
5 Traté este punto en la conferencia "Fernando Pessoa en Barcelona", realizada en octubre de 2012 en Barcelona. "Edición y deconstrucción en el Livro del desassosssego". El artículo va a ser publicado en breve por el Centro de Filosofía de la Universidad de Lisboa y la Universidad de Barcelona.
} 
heterónimos a todos, porque nos impele a intentar continuar su escritura con miras a cerrar (en forma de libro) o de dar sentido (interpretación).

La escritura sin cerrar sólo se puede explicar si se entiende el Livro como operador imaginario que permite a la escritura proyectarse en un determinado ideal formal. ¿Qué quiere decir exactamente esto? El escritor uruguayo Eduardo Galeano definió la utopía de la siguiente manera:

Ella está en el horizonte dice Fernando Birri. Me acerco dos pasos y ella se aleja dos pasos. Camino diez pasos, y el horizonte se desplaza diez pasos más allá. A pesar de que camine, no la alcanzaré nunca. ¿Para qué sirve la utopía? Sirve para esto: para caminar. (Galeano, 1993:?)

El libro funciona de manera similar en Pessoa, le permite caminar, es decir, escribir. En la medida que no lo termina, más allá de todos los índices e intentos de ordenación, puede continuar escribiendo y este proceso es que el que genera las múltiples identidades ${ }^{6} \mathrm{como}$ señala Calvino:

...e nestas operações a pessoa eu, explícita ou implícita, fragmenta-se em figuras diferentes, num eu que está a escrever e num eu que é escrito, num eu empírico que está às costas do eu que está a escrever e num eu mítico que serve de modelo ao eu que é escrito. $\mathrm{O}$ eu do autor ao escrever dissolve-se: a chamada «personalidade» do escritor é interna ao acto do escrever, é um produto e um modo da escrita. (Calvino, 1967: 215).

Ahora bien, uno de los postulados que anunciábamos al principio es que la escritura se basa en un proceso de selección, desde las letras a las frases pasando por las palabras. Los diferentes momentos de la escritura de Pessoa que hemos visto ponen de manifiesto este postulado. Hay una selección de palabras que dan forma al primer manuscrito. La unión de caracteres en palabras de los siguientes testimonios hace más evidente dicho proceso. El escritor es una máquina que selecciona letras, forma palabras y da forma a un texto.

Também uma máquina escrevente, em que tenha sido inserida uma instrução a condizer, poderá elaborar na página uma "personalidade" de escritor destacada e inconfundível, ou então poderá ser regulada de modo a evoluir ou a transformar "personalidades" por cada obra que compõe. O escritor, tal como tem sido até agora, já é máquina escrevente, ou seja, é-o quando funciona bem: o que a terminologia

${ }^{6}$ Sobre la emergencia de Soares como producto del proceso de escritura se puede leer: "Fernando Pessoa y las máscaras escritas" (GIMÉNEZ, 2012). 
romântica denominava génio ou talento ou inspiração ou intuição não é mais do que o achar a sua via empiricamente, pelo faro, cortando por atalhos, onde a máquina seguiria um caminho sistemático e consciencioso, ainda que velocíssimo e simultaneamente de múltiplas bifurcações. (Calvino, 1967: 215-216).

¿Cómo representar las múltiples bifurcaciones del Livro? Manuel Portela, dentro del proyecto "Nenhum Problema tem Solução um arquivo digital do Livro do Desassossego", define el fragmento como la unidad básica del archivo. Así:

a. Un fragmento se descompone en frases, palabras, signos de puntuación y signos de revisión (que pueden estar asociados a marcadores de tipo textual MT [esto es, que señalan variantes textuales] y marcadores de tipo semántico MS [esto es, que señalan temas o tópicos]).

b. Los marcadores de tipo textual o de tipo semántico pueden ser internos (describen o hacen referencia a un elemento dentro del fragmento o externos a los fragmentos (describen o hacen alusión a todo el fragmento).

c. Cada fragmento forma parte de un conjunto, que es una determinada edición ya creada o por crear.

Todos los editores que se han enfrentado a los textos de Fernando Pessoa han tenido que definir cuestiones de orden teórico, como la especificación del fragmento, para poder enfrentarse al reto que los textos del escritor plantean. ¿Cómo se editan los fragmentos? Sobre la base fragmentaria del Livro, los compiladores han construido copias diferentes de un texto que por su naturaleza parece no tener fin. La edición digital puede ayudar a respetar la pluralidad fragmentaria del autor. Antes, no obstante es necesario remarcar, como dice Sandy Baldwin, que "plain text is never plain" (2013). Esto significa que cualquier codificación electrónica, incluso la que reduce el texto a un código de simple transcripción de caracteres (como ASCII), requiere interpretación. Veamos qué nos dice la codificación informática de un texto sobre la variabilidad textual:

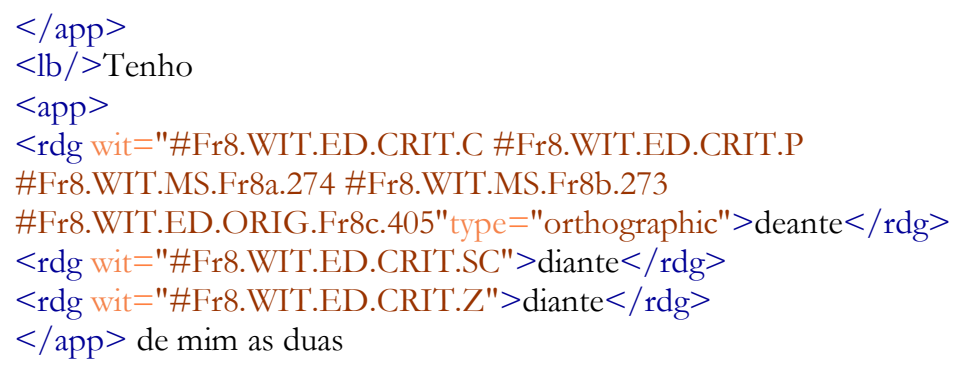




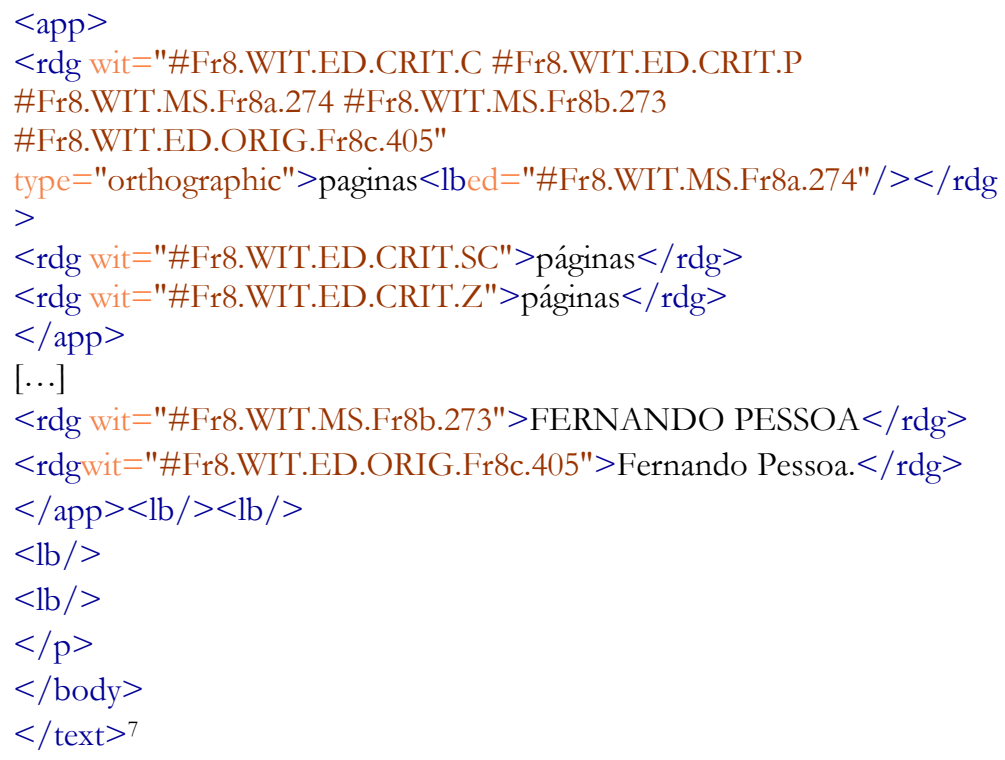

A pesar que pueda resultar molesto para la lectura coloque parte de la codificación del fragmento con la intensión también de poder ofrecer una manera de comparar con los textos editados en las diferentes ediciones. Con la presente codificación informática se da cuenta de los marcadores internos al texto para poder representar las diferentes variables textuales. Por ejemplo vemos como las diferencias entre ediciones por lo que se refiere a la ortografía quedan representadas de la siguiente manera:

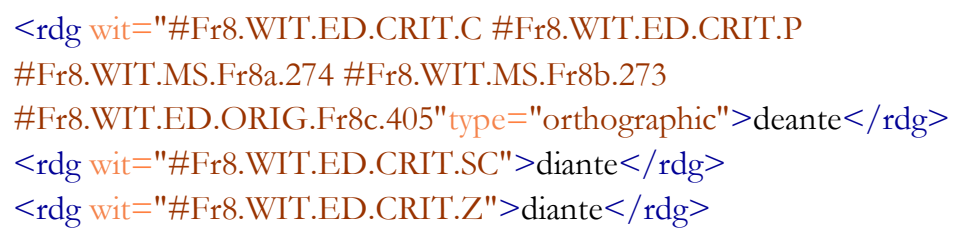

Con esta marcación se está diciendo que tanto los testimonios originales (que siguen las siglas Fr8.WIT.MS.Fr8a.274, Fr8.WIT.MS.Fr8b.273 y Fr8.WIT.ED.ORIG.Fr8c.405) y las ediciones de Coelho y Pizarro (Fr8.WIT.ED.CRIT.C y Fr8.WIT.ED.CRIT.P respectivamente) siguen la palabra 'deante', mientras que las ediciones de Sobral Cunha y de Zenith (Fr8.WIT.ED.CRIT.SC y Fr8.WIT.ED.CRIT.Z, respectivamente) siguen la palabra 'diante'. De esta manera hay una marcación para cada variable textual. Este código es leído por un software que da cuenta de tantas diferencias como sea posible marcar:

${ }^{7}$ Fragmento de acuerdo con la norma TEI P5 (Text Encoding Initiative). 


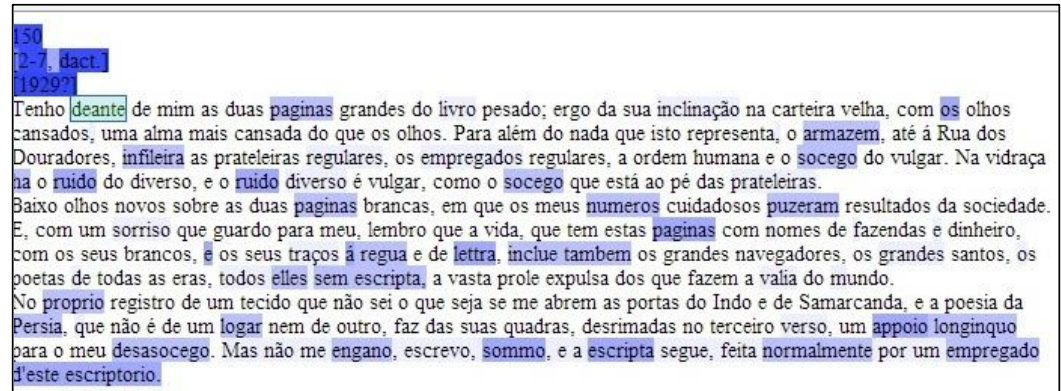

Figura 6. Texto leído en el programa Juxtacommons desarrollado por la Universidad de Virginia.

El fragmento, según se expone en el ejemplo anterior, es la unidad textual que da cuenta de todos los testimonios y de todas las variantes textuales que estos mismos han generado en las diferentes ediciones. La intención de esta marcación es conseguir una forma aún más estricta de poder comparar la escritura de Pessoa y relacionarla con otros fragmentos o textos del escritor. La marcación también permite comparar automáticamente diversas configuraciones editoriales de los fragmentos del Livro. En un archivo digital, como mantiene McGann, la ordenación de los fragmentos no presenta un único centro, todos están hiperligados:

Hypertext provides the means for establishing an indefinite number of "centers," and for expanding their number as well as altering their relationships. One is encouraged not so much to find as to make order and then to make it again and again, as established orderings expose their limits. (McGann, 1996: 29).

La naturaleza de la obra de Pessoa parece encajar a la perfección con los postulados de McGann. Si aceptamos que el Livro, en su especificidad, esto es falta de ordenación, selección y atribución última, es muchos libros, no sólo el de Coelho, el de Sobral Cunha, el de Zenith y el de Pizarro, sino el de todos los lectores que den sentido y todas las posibles lecturas y recorridos que los textos aceptan, entonces se comprende que el Livro es una especie de Aleph borgeano.

La edición de un texto que no tiene fin es una interrupción. Derrida sostiene que el "Libro" (cualquier libro), en cuanto a publicación, funciona como corte, como "interruptor" (1999: 29) a un texto que se presenta infinito. Los subrayados, las substituciones, las tachaduras, etc., son el rastro material de la subjetividad del mutilado Pessoa-Soares (Pessoa, 1986*: 199) que emerge en el proceso de selección. Pero, más allá, la codificación del fragmento con todos los marcadores posibles, tal y como presenta el equipo de Coímbra, también muestra la emergencia de la subjetividad de cada editor 
al señalar (ver las marcas ED.CRIT.C, ED.CRIT.SC, ED.CRIT.Z y ED.CRIT.P en el ejemplo anterior) las decisiones que producen su variante textual. Aún más allá, cada lectura del archivo, en cuanto a selección, será el rastro de un sujeto que crea su propio Livro. Las ediciones de Pessoa figuran y desfiguran en la medida que, al tomar las decisiones a las que están obligadas, establecen una variable textual allí dónde hay más de una. La edición digital aúna los rostros existentes y facilita las condiciones para que los potenciales rostros acontezcan, ofreciendo una experiencia material de la pluralidad del texto sin cierre y, al mismo tiempo, facilitando la experiencia del Livro como potencialidad.

\section{Referencias}

BALDWIN, Sandy (2013). "Between Two Writings: The Materiality and Entropy of Digital Inscription, and the Philosophical Condition of Electronic Literature", (15 de março de 2013, seminário lecionado na Faculdade de Letras da Universidade de Coimbra).

CALVINO, Italo (1986). "Cibernética e Fantasmas (Apontamentos sobre a ficção como processo combinatório) [1967]”, Ponto Final: Escritos sobre Sociedade e Literatura, Trad. José Colaço Barreiros, Lisboa: Teorema, pp. 207-225

DERRIDA, Jacques (1999). No escribo sin luz artificial. Versión española de R. Ibañez y M. J. Pozo. Valladolid: Cuatro Ediciones.

DRUCKER, Johanna (2006). "Graphical Readings and the Visual Aesthetics of Textuality”, Text, vol. 16: 267-276.

FOUCAULT, Michel (2005). Arqueología del saber. México: Ed. Siglo XXI.

GALEANO, Eduardo (1993). Las palabras andantes. Barcelona: Ed. Siglo XXI de España.

GALHOZ, Maria Aliete (1985). "Fernando Pessoa e a ficção(?) de um real (quotidiano) para Bernardo Soares no seu Livro do Desassossego" - O pequeno espaço da felicidade", en Actas do 2'Congresso Internacional de Estudos Pessoanos. Porto: Centro de Estudos Pessoanos, pp. 169-177.

GIMÉNEZ, Diego (2009). 'Fernando Pessoa: irrealidad, escritura y desasosiego'.

http://entrefragmentos.wordpress.com/2010/04/16/fernando-pessoairrealidad-escritura-y-desasosiego-i

GIMÉNEZ, Diego (2012). "Fernando Pessoa y las máscaras escritas", en Pessoa Plural, (No 2/fall - 2012), Brown University, pp. 155-173.

DE MAN, Paul (2007). La retórica del romanticismo. Versión española de Julián Jiménez Heffernan. Madrid: Akal.

DE MAN, Paul (1990). La resistencia a la teoría. Versión española de Elena Elorriaga y Oriol Francés. Madrid: Visor.LIND, Georg Rudolf (1970). Teoría poética de Fernando Pessoa. Porto: Inova. 
MCGANN, Jerome (1996). "The Rationale of HyperText", Text, vol. 9: 1132.

PESSOA, Fernando (2010). Livro do Desasocego. Edición de Jerónimo Pizarro. Lisboa: Imprensa Nacional-Casa da Moeda. 2 tomos. Edición Crítica de Fernando Pessoa, serie mayor, vol. XII.

(1966). Páginas Íntimas e de Auto-Interpretação. Lisboa: Ática.

(1982). Livro do Desassossego. Edición de Jacinto do Prado Coelho. Lisboa: Ática.

(1986). Livro do Desassossego. Edición de António Quadros. Sintra: Europa-América.

(2003). The Book of Disquiet. Edición de Richard Zenith.London: Penguin Books.

(2008). Livro do Desassossego. Edición de Sobral Cunha. Lisboa: Relógio d'Água.

(2009). Livro do Desassossego. Edición de Richard Zenith. Lisboa: Assírio \& Alvim.

(1986*). Escritos Íntimos, Cartas e Páginas Autobiográficas. Lisboa: EuropaAmérica.

SEPÚlVEDA, Pedro (2010). "O Livro de Caeiro", in Diacrítica, No 24.3: 387-412.

SEPÚlVEDA, Pedro (2012). Os Livros de Fernando Pessoa. Tesis-doctoral. Lisboa: Faculdade de Ciências Sociais e Humanas da Universidade Nova de Lisboa. URL: http://hdl.handle.net/10362/7420

(C) 2013 Diego Giménez. 